\title{
Resiliência de comunidades rurais: a freguesia de Cernache do Bonjardim, Portugal
}

\author{
Marta Marçal Gonçalves \\ Universidade do Algarve - Faro - Portugal \\ María Teresa Pérez Cano \\ Universidad de Sevilla - Sevilla - España \\ Stefan Rosendahl \\ Instituto Superior Dom Dinis - Marinha Grande - Portugal
}

\section{Resumo}

A temática abordada neste artigo é a resiliência de uma comunidade rural, situada no interior de Portugal continental. $O$ objectivo foi retratar a resiliência desta comunidade e elaboraremse análises posteriores para percepção dos pontos positivos e negativos apresentados. Actualmente a resiliência de uma comunidade é bastante discutida, mas não foram encontrados em Portugal, estudos que quantificassem ou permitissem percepcionar a real resiliência de uma comunidade rural. Para se conseguir este objectivo, foram feitas pesquisas bibliográficas que ajudaram a compreender esta questão e foram elaborados inquéritos, com base no método utilizado, para se conseguir delinear a questão. $O$ principal resultado foi a confirmação do que se intuía na prática, o que veio a confirmar-se à posteriori: que a freguesia em estudo tem uma resiliência inata, mas que esta corre o risco de desaparecer devido ao problema da desertificação.

Palavras-chave: Comunidades resilientes. Desenvolvimento regional. Análise SWOT. Cernache do Bonjardim. Portugal.

\section{Rural communities' resiliency: the parish of Cernache do Bonjardim, Portugal}

\section{Abstract}

The theme addressed in this article is the resilience of a rural community, located in the interior of mainland Portugal. The objective was to portray the resilience of this community and to elaborate later analyses to perceive the positive and negative points presented. Currently, the resilience of a community is highly discussed, but no studies were found in Portugal that quantified or allowed to perceive the real resilience of a rural community. In order to achieve this objective, bibliographical research was done to help understand this issue, and surveys were developed based on the method used to delineate the issue. The main result was the confirmation of what was intuited in practice, which came to be confirmed lately: that the parish in study has an innate resilience, but that it runs the risk of disappearing due to the problem of desertification.

Keywords: Resilient communities. Regional Development. SWOT Analysis. Cernache do Bonjardim. Portugal. 
Resiliencia de comunidades rurales: la pedanía de Cernache do Bonjardim, Portugal

\section{Resumen}

El tema abordado en este artículo es la resiliencia de una comunidad rural, ubicada en el interior del Portugal continental. El objetivo fue retratar la resiliencia de esta comunidad y elaborar posteriormente el análisis para la percepción de los puntos positivos y negativos identificados. Actualmente la resiliencia de una comunidad es un tema muy debatido, aunque no encontramos en Portugal estudios que cuantifiquen y permitan percibir la auténtica resiliencia de una comunidad rural. Para lograr este objetivo, se realizaron investigaciones bibliográficas que ayudaron a comprender el estado de la cuestión, se elaboraron encuestas, en base a la metodología utilizada, todo ello para conseguir delimitar nuestro objetivo. El principal resultado fue la confirmación de lo que se intuía en la práctica y se confirmó a posteriori: que la pedanía en estudio tiene una resiliencia innata, aunque ésta corre el riesgo de desaparecer debido al problema de la desertificación.

Palabras clave: Comunidades resilientes. Desarrollo regional. Análisis DAFO. Cernache do Bonjardim. Portugal.

\section{Introdução, contextualização e metodologia}

O presente artigo resulta de uma tese de doutoramento (GONÇALVES, 2016) desenvolvida entre 2011 e 2016, contendo, entre outros aspectos, uma caracterização da resiliência da comunidade rural da freguesia ${ }^{1}$ de Cernache do Bonjardim, Portugal, pelo que se aconselha a sua consulta, sempre que se pretenderem mais detalhes do que aqui é exposto.

Esta freguesia, localizada no interior de Portugal continental, apresenta o que se intuiu como uma resiliência inata: apesar de todos os revezes que os habitantes sofrem e têm sofrido, sempre reagem, reorganizam-se e conseguem sobreviver.

O tipo de perturbações que tem vindo a sofrer, negativas, são do tipo "fastmoving" (rápidas) e do tipo lento "slow-burn" (PIKE; DAWLEY; TOMANEY, 2010): em 1951 sofreram o impacte da construção de uma barragem de albufeira, a jusante, que inundou os melhores campos agrícolas, muito património e aldeias (parcial ou totalmente); em 2017 sofreram o impacte dos catastróficos fogos florestais que queimaram cerca de metade do território. A par destes fenómenos, desde os anos 60 do século XX a freguesia começou a perder, gradualmente, população.

O que se verificou no caso da construção da barragem e no caso dos incêndios florestais, foi que a população reagiu, reorganizou-se e sobreviveu, o que demonstra que a comunidade cernachense tem uma resiliência inata que veio a ser confirmada pelas análises efectuadas neste trabalho. A questão do despovoamento é um problema que avança muito lentamente, não Ihe sendo atribuída a importância devida pois passa quase despercebido.

Pretende-se expor neste artigo o método utilizado e as suas principais conclusões, aplicadas à população da freguesia em questão.

A base teórica prende-se com o conceito de resiliência aplicada a comunidades rurais. Insiste-se na palavra rural porque a realidade vivida nas grandes cidades e no campo é completamente diferente.

\footnotetext{
${ }^{1} \mathrm{O}$ território considerado para o estudo é definido segundo a Carta Administrativa e Organizacional
} de Portugal, CAOP2011. 
O objectivo principal foi a avaliação da resiliência da comunidade cernachense, definindo-se o que se designou por "retrato da resiliência da comunidade" e a sua posterior interpretação, através de análises do tipo SWOT. Para tal, adoptou-se o método proposto por Colussi (2000). À data da elaboração desta análise, foi o único método encontrado para tentar caracterizar a resiliência de comunidades rurais. Sendo um método canadiano, foi necessário efectuarem-se algumas adaptações ao caso português, nomeadamente em relação à legislação, já que a estrutura política dos dois países tem algumas diferenças. Este método define cinco funções-chave para a vitalidade da economia local e regional da comunidade, baseando-se em quatro dimensões da resiliência e vinte e três características comuns às comunidades resilientes. As dimensões relacionam-se com as características e as características também se relacionam entre si permitindo a elaboração de análises do tipo SWOT, como se descreve adiante. Para se aplicar o método referido anteriormente, foi necessário efectuar inquéritos que permitiram uma análise qualitativa.

No decorrer do trabalho encontraram-se algumas limitações, nomeadamente a relutância, por parte dos particulares, em responderem ao inquérito, pois trata-se de uma comunidade relativamente pequena (3000 habitantes, segundo os CENSOS2011), onde todos se conhecem e onde tudo se sabe. Desta forma, ocorreu muita negação em responder aos inquéritos, que apenas foram respondidos por pessoas que ocupavam cargos nas várias instituições, como as de ensino, bombeiros, sociais, etc.

Em 2016, quando este trabalho foi apresentado (GONÇALVES, 2016), ainda não existia nenhum semelhante em Portugal, pelo que foi pioneiro, inovador e original.

Este trabalho pode ajudar esta comunidade a fazer uma auto-análise, vendo os seus pontos positivos e negativos, tornando-se mais coesa e a projectar, dentro dos limites que tem, o seu futuro. Dando uma alternativa de se ter um pensamento diferente, com outra atitude, as atitudes dos cernachense poderão melhorar.

Verificou-se grande espectativa com o trabalho desenvolvido, sendo evidente que os cernachenses pretendem que Ihes apresentem sugestões e alternativas para que possam seguir em frente e perspectivar algum futuro. Esse é um dos objectivos a atingir.

\section{A freguesia de Cernache do Bonjardim}

A freguesia de Cernache do Bonjardim situa-se na parte Oeste do município da Sertã localizado na parte Oeste do distrito de Castelo Branco, em Portugal continental (Figura 1). É a segunda freguesia mais populosa do concelho da Sertã. 
Figura 1 - Localização do distrito de Castelo Branco (esquerda) e do município da Sertã (direita)

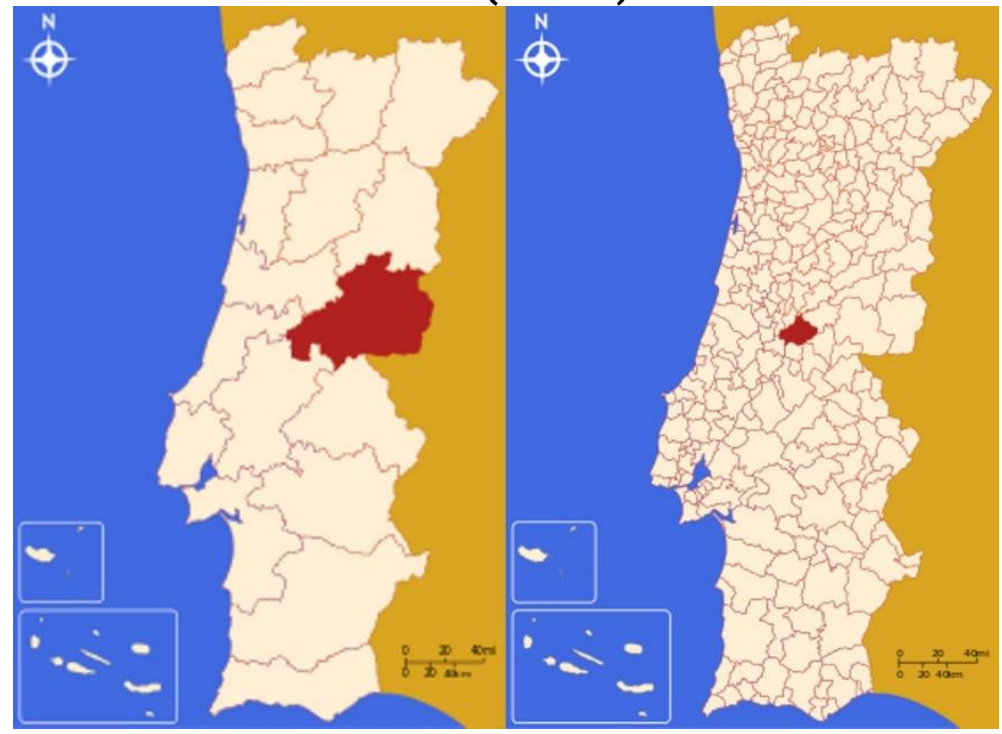

Fonte: Wikipedia (acedido a 15/2/2019).

É limitada a Oeste e Norte pelo rio Zêzere, um dos maiores rios totalmente português e a Sul pela ribeira da Sertã (Figura 2). O rio Zêzere, com as suas barragens hidroeléctricas de albufeira, influencia esta freguesia, nomeadamente a barragem do Castelo do Bode, a jusante, e a barragem da Bouçã, a montante. A albufeira do Castelo do Bode é a principal responsável pela alteração sofrida pelo leito das linhas de água principais deste território (GONÇALVES; ROSENDAHL, 2010).

Figura 2 - 0 território da freguesia de Cernache do Bonjardim com a vila e as principais linhas de água assinaladas

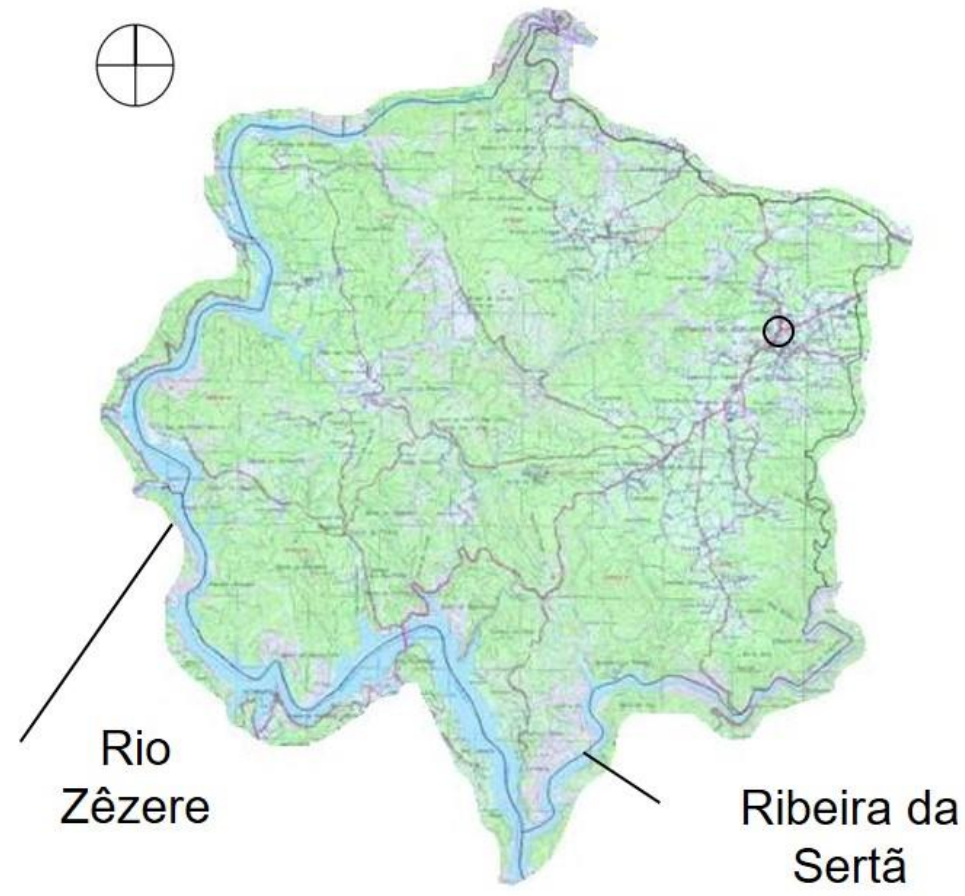

Fonte: baseado nas cartas militares 1:50000 de 2003. 
Este território é constituído, principalmente, por zonas de serra. Sendo uma freguesia essencialmente rural, onde cerca de $50 \%$ da população activa se dedica à agricultura de autoconsumo, o sector florestal também tem lugar de destaque na economia da região. No entanto, o sector terciário tem vindo a ganhar alguma importância em relação ao sector primário (ib.).

As vias de comunicação rodoviárias são constituídas pela EN 238 (Estrada Nacional), que liga Tomar (a Sudoeste) à Sertã e pela ligação da Sertã ao IC 8 (Itinerário Complementar), que atravessa o território português nesta zona de Este (desde Pombal) para Oeste, que depois prossegue para a A 23 (Auto-estrada) - IP 2 (Itinerário Principal) até à fronteira e Vilar Formoso, a Nordeste. Apesar da melhoria das acessibilidades a partir da sede do Concelho, as que servem a freguesia em estudo são ainda deficitárias: a EN 238, muito frequentada pois é a ligação mais acessível para Lisboa e para a estação ferroviária mais próxima (situada em Tomar), apresenta um traçado tortuoso e cheio de curvas porque o terreno é muito acidentado, sendo uma estrada de serra. Apesar de tudo, o seu piso está num estado razoável.

Deveria ser dada mais atenção a estas ligações rodoviárias para fora da freguesia, pois os transportes públicos não são muito frequentes e são morosos; não existe caminho de ferro; só os poucos locais junto à ribeira da Sertã e ao rio Zêzere conseguem usufruir da rede fluvial para se deslocarem. Todas estas dificuldades estrangulam a economia local.

\section{Questões sobre o desenvolvimento de zonas rurais}

Quando falamos de zonas rurais, como a de Cernache do Bonjardim, estamos a falar nas designadas "zonas rurais desfavorecidas" ou ZRD, definidas como "zonas de baixo potencial de capital humano, estruturas produtivas pobres e um ambiente económico e social deprimido" (MOREIRA, 2010, p. 1329), existentes em Portugal, que, sob o ponto de vista territorial são muito importantes mas que, do ponto de vista populacional, têm uma importância muito reduzida; é exactamente nestas regiões, onde a freguesia de Cernache do Bonjardim se insere, que é urgente reforçar a resiliência comunitária e, noutra escala, a regional.

Assim, sob o ponto de vista económico, o facto de não serem atractivas para a fixação de empresas, não gerarem liquidez e não terem mercados, somado à tendência para se aplicar um modelo generalizado, do tipo one fits all (um modelo serve a todos), que não funciona nestes casos, obriga a que seja necessária uma nova postura e abordagens alternativas, em relação a este tipo de territórios. Estas são questões que não são colocadas nem se tem atribuído a importância enorme que têm no contexto das ZRD, já que cada comunidade, em função das suas características, origina diferentes interpretações às funções empresariais (ib.).

As estratégias de desenvolvimento devem criar condições para fazer frente ao declínio socioeconómico e incentivar iniciativas para desenvolver a comunidade economicamente, demonstrando uma atitude pró-activa e não reactiva. A abordagem mais adequada é uma abordagem endógena, onde as facetas da comunidade rural se articulam com o objectivo de se desenvolver, construindo capacidades, conjugando as diversas dimensões comunitárias, como a cultural, social, 
histórica, técnica, económica, e a valorização dos seus recursos endógenos, a partir de uma economia de pequena escala e flexível (NATÁRIO; BRAGA; REI, 2010).

Em relação ao desenvolvimento regional endógeno, interessa "saber como as regiões podem gerar mecanismos endógenos de criação de riqueza com base nos seus recursos específicos" (ib., s.p.).

Vários autores (CORREIA; FIGUEIREDO, 2010; FERNANDES, 2010b; NATÁRIO; BRAGA; REI, 2010; SÁNCHEZ ARROYO; HERRERA PEREA, 1997) defendem que a valorização dos produtos locais é fundamental para o desenvolvimento rural, dinamizando a economia local. Estes produtos podem ser os tradicionais ou a sua interpretação modernizada, utilizando as técnicas tradicionais, por exemplo.

Como forma de valorização destes produtos tradicionais, pode-se recorrer ao branding (marca registada) dos produtos e da região, como a criação de uma marca territorial ou uma denominação de origem, aproveitando o sentido de identidade como aspecto diferenciador de uma região (PACHON; MARTíNEZ, 2011).

É por isso que, quer Moreira (2010), quer Colussi (2000) defendem que é muito importante a identificação de que tipo de empresas interessam e são necessárias e quais os recursos de que a comunidade dispõe para que essas empresas possam ser bem-sucedidas. Neste tipo de território, como o de Cernache do Bonjardim, tão ligado à terra e à agro-pecuária, os sistemas socio ecológicos ainda têm uma importância fundamental.

A crise económica veio confirmar que a política económica globalizante, defendida por Margaret Thatcher, designada TINA² não funciona nestes casos, onde o impacto na comunidade, produzido pela falência de uma grande empresa pode ser fatal, sendo a filosofia LOIS 3 muito mais apropriada, impulsionando e consolidando a resiliência comunitária.

A resiliência comunitária defende que as decisões e a gestão dessa comunidade devem ser do tipo bottom-up (de baixo para cima) e não top-down (de cima para baixo), como tem sido até agora. São as pessoas que constituem a comunidade que devem decidir sobre a gestão do seu território e não apenas aceitar passivamente as ordens que vêm de um governo, centralizado na capital e alheio aos problemas dos pequenos municípios e freguesias, já que nem sempre as soluções vindas do topo dão resposta às necessidades e desafios locais.

$O$ envolvimento do Estado nas comunidades rurais faz com que haja um menor envolvimento dessa comunidade, e, regra geral, rejeitam a autoridade externa, tendendo a conservar a sua forma de actuar tradicional. Deste modo, é mais adequado deixar que estas comunidades controlem e giram os seus recursos

\footnotetext{
2 TINA (There Is No Alternative): provém da invocação de Margaret Thatcher "there is no alternative to global economy!”. É uma política económica que tem três grandes estratégias, que são: a) atrair o maior número de grandes empresas/fábricas para a sua região; b) exportar os bens produzidos na sua região para tão longe e tão amplamente quanto possível, pois baseia-se na concepção de que as exportações são a única forma de obter riqueza "real" na sua comunidade; c) convencer as empresas locais de que a) e b) são do seu maior interesse (SHUMAN, 2011).

3 LOIS (Local Owned business; Import-Substituting development): é uma política económica que enfatiza: $L O=$ empresas de proprietários locais, ou seja, o controle da maioria das empresas é feito na comunidade onde a empresa opera e IS = desenvolvimento de substituição das importações, um termo dos economistas para significar auto-suficiência (ib.).
} 
(CORREIA; FIGUEIREDO, 2010), o que é exactamente a filosofia da resiliência comunitária.

Desde 1996 que as zonas rurais e os seus habitantes são vistos como uma riqueza, tendo a capacidade de serem zonas competitivas (A DECLARAÇÃO DE CORK, 1996); o que outrora era designado como "atraso" é exactamente o que hoje constitui as "potencialidades" (FERNANDES, 2010a) que tornam cada comunidade única, desempenhando um papel importante na coesão e equidade dos territórios (NATÁRIO; BRAGA; REI, 2010).

No entanto, estes territórios sofrem pressões, se, por um lado, têm de se adaptar à sociedade moderna e às exigências actuais por outro lado, não podem perder a sua mais-valia que é exactamente a sua ruralidade (CORREIA; FIGUEIREDO, 2010). Do mundo rural espera-se que mantenha o seu passado, as suas tradições, a sua identidade, por vezes numa ideia romantizada dos urbanitas, e, simultaneamente, tem de garantir a sustentabilidade, a natureza, o futuro, entre outras coisas (FERNANDES, 2010a), o que constitui um desafio constante e difícil.

Deve, contudo, chamar-se a atenção para o perigo da monoactividade que pode ter consequências muito graves em comunidades pequenas como é a de Cernache do Bonjardim, ficando vulneráveis e dependentes das variações do mercado e constituindo uma utilização parcial dos recursos endógenos, tornando a comunidade mais frágil do ponto de vista resiliente (SÁNCHEZ ARROYO; HERRERA PEREA, 1997).

\section{Resiliência da comunidade}

Uma comunidade é tanto mais resiliente quanto melhor conseguir dar resposta, superar, reorganizar-se e sobreviver a impactos como sejam roturas, crises e catástrofes.

Edwards (2011) defende que as comunidades têm demonstrado a sua resiliência nessas situações, podendo-se afirmar que, as comunidades têm uma resiliência inerente e que a resposta mais eficaz a essas situações é a resposta dos locais, que têm de sobreviver nessas situações, encontrando soluções mais apropriadas.

Collussi (2000) afirma que todas as comunidades têm características próprias que podem restringir ou permitir a sua resiliência e mostrou que há determinadas características que são comuns às comunidades resilientes. Daqui resulta a importância em se conhecerem os pontos positivos e negativos de cada comunidade, definindo claramente as prioridades a atingir e porquê. A mesma autora admite que a resiliência é uma qualidade que as comunidades possuem, que não é estática, podendo ser desenvolvida e reforçada ao longo do tempo.

Para dos Santos (2009, p.16):

a resiliência depende da capacidade de adaptação e no que diz respeito às comunidades humanas, tal capacidade depende em larga medida da forma como estas conseguem aprender colectivamente e convergir em função de objectivos comuns.

Mas para "aprender colectivamente" é necessário fazer uma análise da situação sob a perspectiva da resiliência. É essa análise que o "retrato da resiliência da comunidade", proposto por Colussi (2000), nos permite fazer. 


\section{Os impactos sofridos na freguesia de Cernache do Bonjardim}

\subsection{Impacto devido à água}

O rio Zêzere foi sempre uma fronteira natural da freguesia muito utilizada, quer como via de comunicação entre as margens, quer como uma forma de subsistência, pois as actividades da pesca, garimpagem, aproveitamento como força motriz para a moagem e irrigação, entre outras, eram muito frequentes.

Em 1951 a barragem do Castelo do Bode, uma barragem de albufeira situada no rio Zêzere, a jusante da freguesia em estudo, com uma área aproximada de 32.9 km2 (AGÊNCIA PORTUGUESA DO AMBIENTE, [s.d.]) é terminada, enchendo-se a sua albufeira e submergindo todos os campos nas margens do "rio velho", os "nateiros", campos de cultivo muito férteis, sinónimo de riqueza para os seus proprietários.

Com o enchimento desta albufeira, toda a paisagem mudou, tal como a fauna existente no rio e representando um enorme impacto na população da freguesia, tão "ligada à terra", pois muito rapidamente se perderam excelentes terras de cultivo, as azenhas e moinhos, cuja força motriz era a água, ficaram submersos e as pessoas não tinham onde "moer o pão", que é a expressão local para moer o trigo para fazer pão (GONÇALVES; ROSENDAHL, 2011).

Passou-se de um rio estreito e selvagem para um enorme espelho de água, com uma paisagem igualmente deslumbrante. Do "rio velho" apenas chegaram até nós poucas fotografias e algumas pinturas e desenhos; o "rio novo" pode ser visto por quem percorra estas paragens (Figura 3).

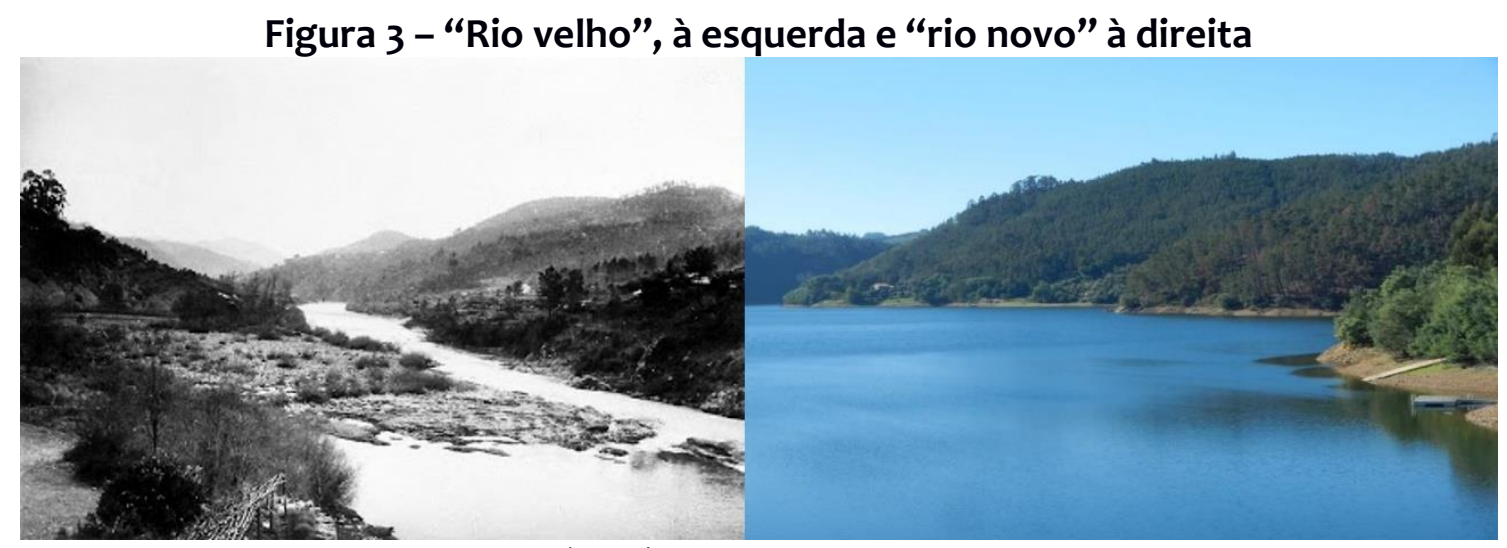

Fonte: imagem da esquerda Mendes (2009). 
Desde essa altura, até aos dias de hoje, como pode ser facilmente verificado para quem visita este território, a população de Cernache conseguiu adaptar-se à nova situação, reagir, reorganizar-se e sobreviver. Foi resiliente.

\subsection{Impacto devido à migração}

A migração, quer seja para outras partes do País, quer seja para o estrangeiro, tem vindo a aumentar com o consequente despovoamento deste território.

Na história de Portugal o principal período que fez diminuir a população da freguesia de Cernache coincide com o período da Guerra Colonial (1961-1974) onde houve um êxodo enorme da população portuguesa, principalmente masculina, para a Europa, em especial França, não só à procura de melhores condições de vida, como para fugir à tropa e à quase certa ida para a guerra nos territórios do Ultramar (Figura 4). Para a I Grande Guerra (1914-18) não devem ter perecido muitos homens desta freguesia, pois a variação de população nesse período parece ser quase nula. 0 período assinalado no final do séc. XIX coincide com um período de grande êxodo dos cernachenses para o Brasil, em especial para a zona de Manaus, onde se fizeram grandes fortunas; no entanto, estes emigrantes voltaram para a sua terra, trazendo meios económicos para desenvolver a sua comunidade, o que se verificou realmente: quer ao nível económico, quer ao nível intelectual, Cernache deu um "pulo" enorme nesta época. Isto é fácil de perceber se se pensar que Cernache era uma aldeia perdida no interior de Portugal, mas onde havia uma escola primária feminina, um teatro, uma escola de música, a sede de um banco, entre outras mais valias, e onde o movimento postal - indicador do desenvolvimento económico - era superior a muitas outras freguesias da sua municipalidade, mesmo somadas. Não se obtiveram dados para explicar a quebra de população entre 1920 e 1930.

Nesse período áureo verificou-se um aumento gradual da população, mas, desde 1960, quando atingiu o ponto máximo com 5041 habitantes, a diminuição gradual tem sido uma constatação, tendo actualmente, segundo os CENSOS de 2011, 3052 habitantes.

Este é um impacto lento, gradual, o qual seria importante reverter.

\subsection{Impacto devido ao fogo}

Nesta freguesia havia a tradição de plantar um pinhal sempre que nascia um filho para que se pudesse cortar e vender a madeira quando esse filho casasse e construísse a sua casa. Com a crescente produção da pasta de papel em Portugal, plantar eucalipto tornou-se muito mais atractivo, já que se trata de uma árvore de crescimento rápido, onde se vê um retorno mais rápido do investimento do que se se plantarem pinheiros (GONÇALVES; ROSENDAHL, 2010). Infelizmente, o eucalipto é uma árvore facilmente inflamável, tal como o pinheiro. 
Figura 4 - População residente entre 1864 e 2011 na freguesia de Cernache do Bonjardim

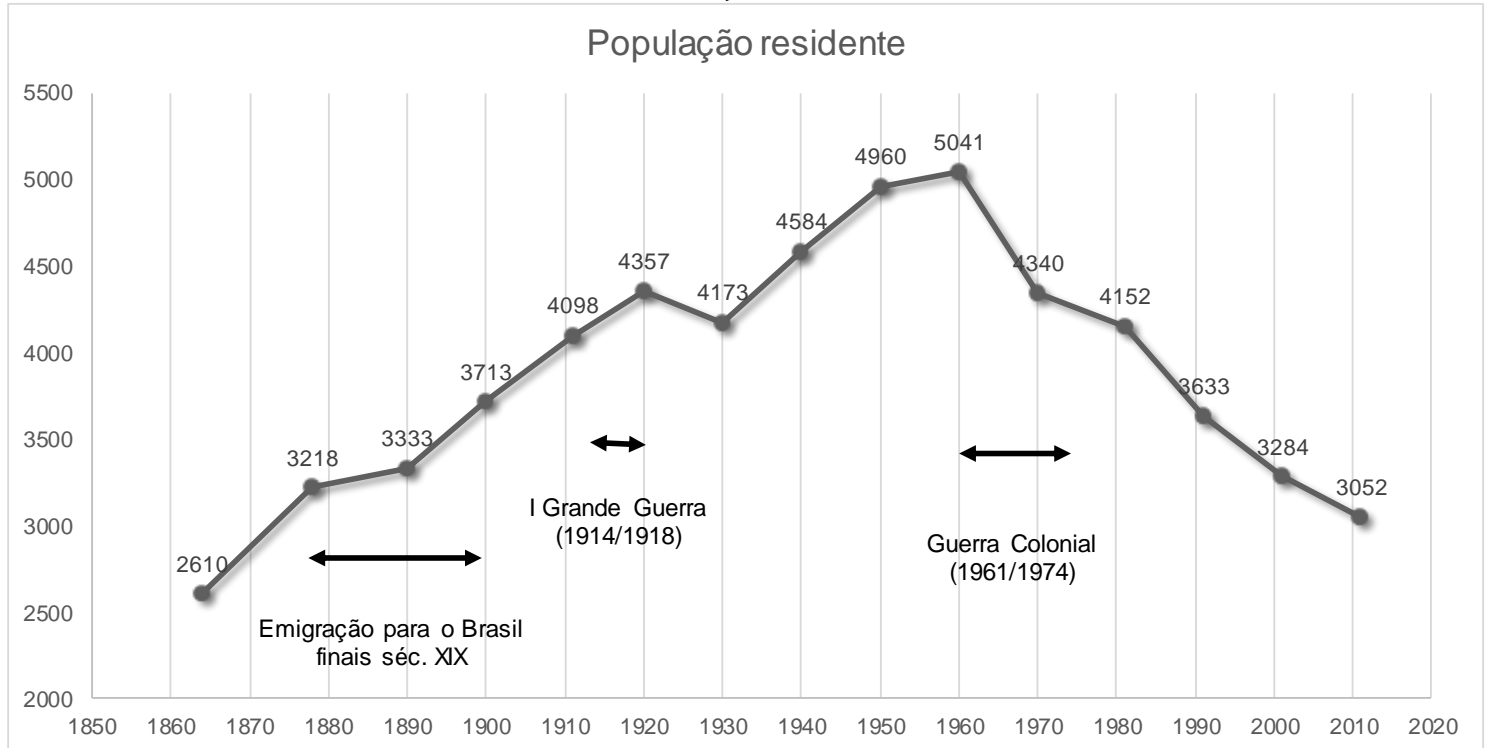

Fonte: elaborado a partir dos dados do INE.

Todos os Verões este território é fustigado pelos incêndios florestais, mas o de 2017 foi particularmente catastrófico. Um incêndio florestal que começa numa municipalidade na zona, alastra-se para as demais e chega à freguesia de Cernache. Neste incêndio morreram cerca de 64 pessoas, tendo sido considerado o mais mortal em Portugal (GRANDES INCÊNDIOS EM PORTUGAL. UMA HISTÓRIA QUE COMEÇOU EM 1986, 2017) e o $11^{\circ}$ mais mortal no mundo, desde 1900 (BARROS, 2017); 47 das vítimas mortais morreram na estrada enquanto tentavam escapar ao fogo. A área ardida foi de cerca de 53000 ha (DIÁRIO DE NOTÍCIAS, 2017) e era possível ver o fogo nas imagens de satélite fornecidas pela NASA.

Vários foram os factores que contribuíram para esta catástrofe, um dos quais foi o sistema de coordenação utilizado, que tem provado sistematicamente não funcionar correctamente e ser ineficaz, ter gerado uma confusão entre as corporações de bombeiros. As pessoas dos locais tentavam desesperadamente salvar os seus bens e ajudarem-se uns aos outros: quando havia água, era impossível tirá-la de dentro dos poços porque as bombas são eléctricas e os cabos estavam queimados... quando havia electricidade, as mangueiras estavam queimadas... quando o fogo vinha, fustigado pelo vento e se conseguia extingui-lo, o vento mudava e voltava tudo ao mesmo... de uma forma ou de outra, o combate era inglório, tendo-se perdido muitos animais domésticos e selvagens, pomares e hortas, principal sustento da população que pratica uma agricultura de autoconsumo para equilibrar as suas escassas finanças familiares (Figura 5). 
Figura 5 - Fios eléctricos incinerados na freguesia em estudo

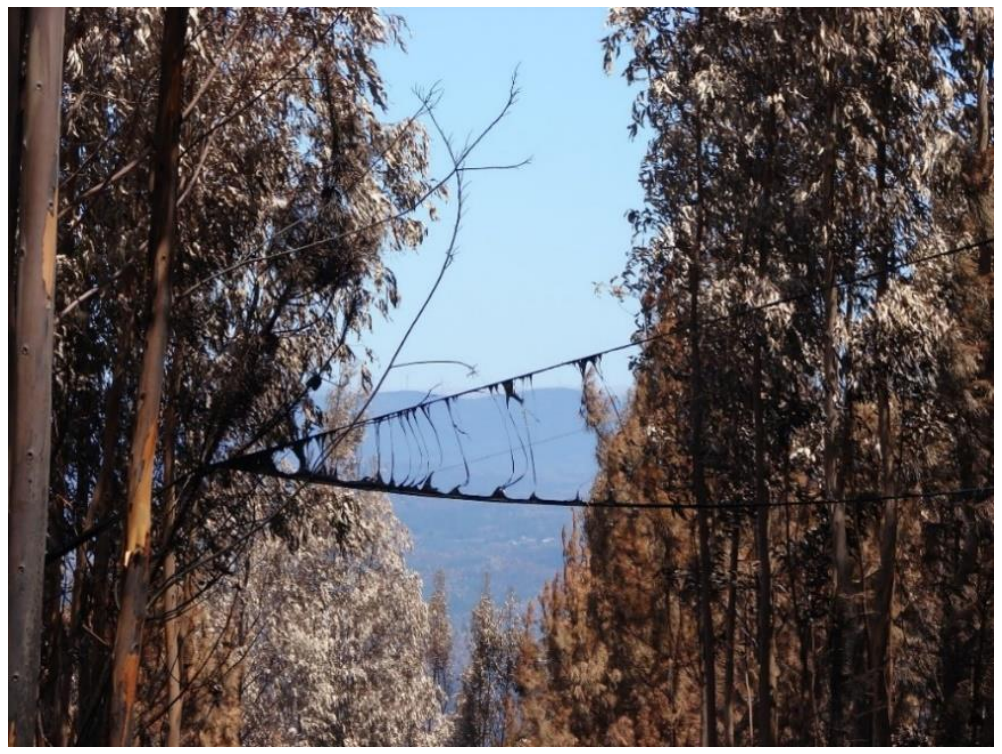

Fonte: autores.

Metade do território da freguesia ficou queimado, mas, felizmente, as perdas verificadas na sua área foram só materiais, apesar do fogo ter estado muito perto das habitações (Figura 6). No entanto, esta catástrofe ficará na memória deste lugar, estando as pessoas ainda a recuperar deste trauma (GONÇALVES; ROSENDAHL; PEREZ-CANO, 2018). O que mais impressionou quem esteve directamente a enfrentar o fogo não foi o cheiro que se fazia sentir, de madeira e animais queimados, mas sim o som que o fogo florestal faz ao avançar, "parecem cavalos a galope, é horrível". Ao fim deste tempo todo, as pessoas afectadas ainda ouvem este som, disseram-nos oralmente.

Figura 6 - Aldeia de Porto dos Fusos, onde se pode ver a distância diminuta entre 0 incêndio e as habitações

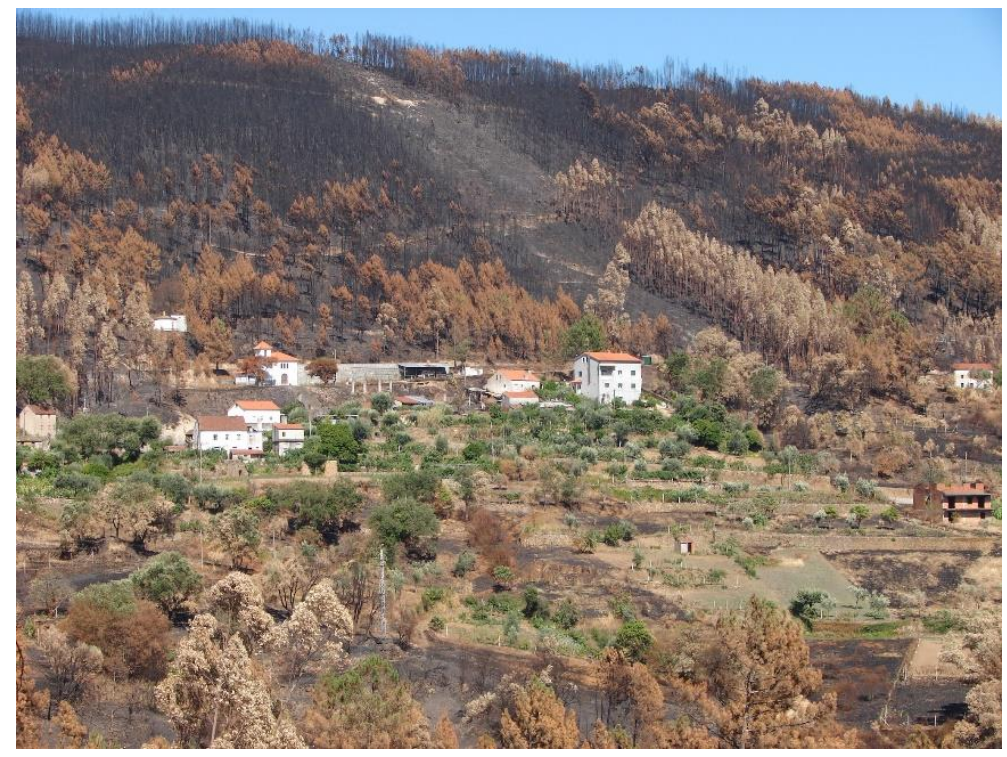

Fonte: autores. 
Novamente, a população de Cernache adaptou-se à nova situação, reagiu, lutou, reorganizou-se e sobreviveu, não tendo havido um aumento do abandono da freguesia devido a este fogo florestal. Apesar de ser o tempo a confirmar e de ainda ter passado pouco tempo desde esta tragédia, a população tem sido resiliente.

\section{0 retrato da resiliência}

O método adoptado para a avaliação da resiliência da comunidade de Cernache do Bonjardim, é prático e simples de utilizar, tendo vindo a apresentar bons resultados no Canadá, de onde é originário, e nos Estados Unidos (COLUSSI, 2000). Este método é constituído por diversas fases ou passos, a saber:

1. Entender o conceito de resiliência;

2. Avaliar a resiliência da comunidade;

3. Documentar os resultados elaborando um "retrato" com o objectivo de definir prioridades locais para investir de uma forma mais optimizada nos recursos da comunidade;

4. Criar um plano - plano CED (Community Economic Development Plan) baseado na economia e nos recursos da comunidade, para definir prioridades para a comunidade e reforçar a resiliência, que não foi feito pois está fora do âmbito deste trabalho.

O plano CED é um plano de desenvolvimento económico, onde são implementadas medidas que tornem a comunidade mais resiliente e mais próspera. Entenda-se "mais próspera" como a geração de maior bem-estar às pessoas da comunidade, não necessariamente mais dinheiro (ib.).

Tendo por base estas quatro fases, pretende-se mostrar outra forma de pensar e ajudar a concentrar os esforços sobre aspectos-chave para a comunidade, baseado no diálogo entre as pessoas. Deste modo, tirando partido dos seus recursos endógenos, fornecem-se meios para incrementar a capacidade da comunidade para conduzir o seu próprio futuro (ib.).

O método adoptado tem por objectivo conseguir o que definiu como as "funções da comunidade": acesso a fundos próprios, acesso ao crédito; construção de capacidades de recursos humanos; capacidade de pesquisa, planeamento e promoção; e infra-estruturas (ib.).

Para se conseguirem analisar e perceber como estão estas funções, são definidas vinte e três características das comunidades resilientes, que nem todas as comunidades têm ou são fortes, as quais se relacionam com as quatro dimensões da resiliência, que são: as pessoas na comunidade; organizações na comunidade; recursos da comunidade; processo comunitário. Os inquéritos foram elaborados com base nestes pontos, fazendo-se a interpretação e relação entre eles. Essas relações permitem a elaboração de análises SWOT.

\section{0 caso da freguesia de Cernache do Bonjardim}

Para se caracterizar e definir o retrato da resiliência da freguesia de Cernache do Bonjardim, foram efectuados inquéritos directos e pesquisa de dados estatísticos, cujos formulários foram fornecidos pelo método adoptado (COLUSSI, 2000) e adaptados para o caso português. 
Com estes elementos, pretende-se efectuar uma análise qualitativa da comunidade. De acordo com a autora do método, para o caso de Cernache, com 3000 habitantes (CENSOS2011), seriam necessários efectuar 15 a 19 inquéritos; foram elaborados 17, o que se considera suficiente para a credibilidade do processo. Os inquéritos foram recolhidos durante o ano de 2013.

Para se efectuarem estes inquéritos, foram tidos em conta os seguintes critérios:

- Diferentes géneros;

- Diferentes grupos etários;

- Se são naturais de Cernache ou, não o sendo, se vivem há mais de 4 anos na comunidade;

- Diferentes sectores de actividade.

Em função destes critérios, os entrevistados são os apresentados na Tabela 1. Pode-se agrupar esta informação em função do género, do grupo etário, da proveniência e do sector de actividade (Tabela 2).

Constata-se que a maioria dos inquiridos foram homens, adultos, naturais da comunidade e que o sector de actividade com mais peso foi o associativismo.

Com base nos inquéritos efectuados, foi possível traçar o "retrato de resiliência", cujos resultados principais, muito sucintamente, são apresentados em seguida.

Em relação às atitudes e comportamentos das pessoas na comunidade, verificaram-se níveis muito elevados de orgulho e sentimento de pertença à comunidade, quer dos jovens, quer dos adultos, mas menor do que nos idosos; não se valoriza o conhecimento e a aprendizagem; a perda de emprego não é pressão suficiente para partirem; nem sempre se envolve a população nas decisões e não compreendem até que ponto é que a sua participação influencia as decisões mais importantes para a freguesia - este ponto verifica-se mais da parte da municipalidade e não da freguesia; existe uma atitude de "poder fazer", abraçando as dificuldades e superando-as com trabalho, estando as pessoas receptivas a novas ideias e maneiras de fazer; preferem não tomar atitude em questões directamente relacionadas com vizinhos; a liderança eleita é diversificada, visionária, representa a comunidade e trabalha para obter o consenso em questões importantes; de um modo geral, esta liderança não partilha o poder executivo; as reuniões comunitárias têm muito fraca participação pública; a auto-suficiência é uma questão que merece mais atenção; o sentido de identidade, muito elevado, pode ser um factor positivo no futuro, trazendo de volta casais em idade activa; um motivo de preocupação no futuro prende-se com o diminuto número de famílias em idade activa, existindo poucas crianças com menos de 14 anos. 
Tabela 1. Caracterização dos inquiridos

\begin{tabular}{|c|c|c|c|c|}
\hline Designação & $\begin{array}{c}\text { Género } \\
(\mathrm{M} / \mathrm{F})\end{array}$ & Grupo etário & $\begin{array}{c}\text { Natural/fora } \\
(\mathrm{N} / \mathrm{F})\end{array}$ & $\begin{array}{c}\text { Sector de } \\
\text { actividade }\end{array}$ \\
\hline AJ & $M$ & Adulto & $\mathrm{N}$ & Político/Estado \\
\hline$A L$ & M & $\begin{array}{l}\text { Com menos de } 18 \\
\text { anos }\end{array}$ & $\mathrm{N}$ & Ensino \\
\hline BO & $\mathrm{F}$ & Jovem adulto & $\mathrm{F}$ & Social \\
\hline FR & $\mathrm{F}$ & Adulto & $\mathrm{F}$ & Social \\
\hline GR & $M$ & Jovem adulto & $\mathrm{F}$ & Político/Estado \\
\hline IG & $M$ & Adulto & $\mathrm{N}$ & Social \\
\hline LCBD & $M$ & Adulto & $\mathrm{N}$ & Social \\
\hline LCBU & $\mathrm{F}$ & Idoso & $\mathrm{N}$ & Reformado \\
\hline PA & $\mathrm{F}$ & Idoso & $\mathrm{N}$ & Político/Estado \\
\hline PJ & $M$ & Adulto & $\mathrm{N}$ & Político/Estado \\
\hline PR & $M$ & Adulto & $\mathrm{F}$ & Ensino \\
\hline RFC & $M$ & Adulto & $\mathrm{N}$ & Associativismo \\
\hline RFCP & $M$ & Adulto & $\mathrm{N}$ & Associativismo \\
\hline RLQ & $M$ & Adulto & $\mathrm{N}$ & Associativismo \\
\hline SDN & $M$ & Idoso & $\mathrm{N}$ & Associativismo \\
\hline SJ & $\mathrm{F}$ & Adulto & $\mathrm{N}$ & No activo \\
\hline TM & $M$ & Adulto & $\mathrm{N}$ & Associativismo \\
\hline
\end{tabular}

Fonte: autores.

Quanto às atitudes e o comportamento das organizações na comunidade, a maioria dos inquiridos partilha da opinião de que a comunidade tem alguma capacidade organizacional, principalmente na capacidade de recursos humanos, facilitando o acesso a cursos profissionalizantes; existe cooperação positiva entre as organizações e o conflito, quando existe, é bem gerido; o acesso a fundos próprios, a capacidade de pesquisa, planeamento e promoção da freguesia, infra-estruturas e acesso ao crédito satisfazem moderadamente; houve referência a má gestão de fundos próprios e informação deficiente quando se procuravam, referindo-se principalmente ao município.

Tabela 2. Caracterização dos inquiridos por género, grupo etário, proveniência e sector de atividade

\begin{tabular}{|c|c|c|}
\hline \multicolumn{3}{|l|}{ Género } \\
\hline Homens & 12 & $71 \%$ \\
\hline Mulheres & 5 & $29 \%$ \\
\hline \multicolumn{3}{|l|}{ Grupo etário } \\
\hline Idoso & 3 & $17 \%$ \\
\hline Jovem com menos de 18 anos & 1 & $6 \%$ \\
\hline Adulto & 11 & $65 \%$ \\
\hline Jovem adulto & 2 & $12 \%$ \\
\hline \multicolumn{3}{|l|}{ Proveniência } \\
\hline De fora da comunidade, mas a viver há mais de 4 anos & 4 & $24 \%$ \\
\hline Natural da comunidade & 13 & $76 \%$ \\
\hline \multicolumn{3}{|c|}{ Por sector de actividade } \\
\hline Social & 4 & $24 \%$ \\
\hline Associativismo & 5 & $29 \%$ \\
\hline Ensino & 2 & $12 \%$ \\
\hline Político/Estado & 4 & $24 \%$ \\
\hline Reformado & 1 & $6 \%$ \\
\hline No activo & 1 & $6 \%$ \\
\hline
\end{tabular}

Fonte: autores. 
A análise do conhecimento e utilização dos recursos da comunidade mostrou que cerca de $40 \%$ da força laboral está activa, trabalhando para o Estado ou para os cinco maiores empregadores, tendo actividades diversificadas, não sendo de recear um forte impacto no caso de um dos empregadores sair da comunidade; existe muito auto-emprego (cerca de 9,2\% da força laboral); verificou-se que $60 \%$ dos cinco maiores empregadores são naturais da comunidade e actuam em áreas diferentes, o que é muito positivo; a comunidade está receptiva a mercados de troca directa e ao desenvolvimento de pequenas empresas, no entanto não há uma estratégia para ajudar as empresas em dificuldades e deveria ser analisado com maior cuidado a razão do encerramento de pequenos negócios; são necessários mais esforços para aproveitar as oportunidades de investimentos externos, analisar a conjuntura, conhecer os possíveis nichos de mercado, conhecer a fuga de bens económicos para fora da freguesia; há problemas com alguns recursos humanos; continuam a pensar que a solução está na atracção de um grande investidor; existe um grande esforço de incentivo e divulgação dos produtos locais.

O pensamento estratégico, a participação e a acção do processo comunitário mostraram que a maioria dos inquiridos acha que não existe nenhum plano CED, o que faz com que não se concentrem esforços em objectivos concretos; há um sentimento de separação entre os órgãos eleitos e os elementos da comunidade; uma cooperação melhor entre as agências de desenvolvimento económico e as de serviço social ajudaria a incrementar a auto-suficiência económica e a identificar e suprimir as barreiras que enfrentam os desempregados.

Com o objectivo de consolidar este "retrato" da comunidade, efectuou-se uma análise SWOT, onde foram identificados os pontos fortes, fracos, oportunidades e ameaças, agrupando-se os resultados sob os aspectos internos (forças e fraquezas) e sob os aspectos externos (oportunidades e ameaças). Tendo por base as quatro dimensões da resiliência, definidas pelo método adoptado, preencheram-se os quatro campos da análise SWOT, definindo-a.

Pretendeu-se, com esta análise, facilitar a percepção do que dependia apenas da comunidade (factores endógenos) e o que não dependia directamente da comunidade (factores exógenos). As principais conclusões foram as que se expõem em seguida.

Há um saldo positivo dos aspectos endógenos, com mais forças que fraquezas. Quanto às questões encontradas, apenas depende da comunidade para serem melhoradas. As questões identificadas, foram: existe alguma confusão sobre a existência de um plano económico para a freguesia; a educação, em especial a superior não é valorizada; a taxa de analfabetismo não é demasiado preocupante; existe um sentimento geral de entreajuda; o emprego é diversificado; não há receio de abraçar outra profissão; a maioria dos 5 maiores empregadores são de naturais da freguesia; tenta-se envolver toda a gente nas decisões.

Os aspectos exógenos apresentam um saldo negativo, com mais ameaças que oportunidades. Alguns dos aspectos encontrados, não dependendo da comunidade, sendo feito algum trabalho interno, podem ser melhorados para que deixem de ser ameaças, como a fixação de jovens com formação superior, que querem voltar à sua comunidade, mas que se queixam de não existirem oportunidades. As questões identificadas, foram: ameaça por parte da interioridade, pela desertificação, pelo envelhecimento da população; desemprego; perda de infra-estruturas básicas, como 
saúde, correios, etc.; para as campanhas de "comprar local" contribui o forte sentido de identidade e de pertença; existem infra-estruturas de vários géneros, como desportivas, religiosas, etc.; existem muitas associações e organizações informais sendo a comunidade atractiva para quem vem de fora.

Posteriormente, efectuou-se o que se designou como uma análise SWOT avançada. Como o método adoptado para a definição do retrato de resiliência permitiu relacionar algumas das quatro dimensões da resiliência com algumas das vinte e três características de resiliência, podem-se, assim, seleccionar os elementos que fazem parte da análise SWOT inicial e preencher os campos de intercepção pretendidos, apenas com as características da resiliência que têm relação entre si, excluindo-se as demais.

Esta análise SWOT avançada permite fazer a hierarquização dos pontos identificados, dando importância aos pontos que têm maior impacto e permitindo a concentração de recursos onde realmente terão mais resultado (APRENDA A ANÁLISE SWOT COM MODELO NO EXCEL, [s.d.]).

A análise referida consiste na atribuição de pesos para a relevância de cada item listado na matriz SWOT, sendo $100 \%$ para o que tem mais força em comparação com todos os outros itens e $0 \%$ para contrário, tendo de somar, no final, 100\%, quer para os factores internos como externos. A atribuição desses pesos é feita tendo em consideração o provável impacte dessa característica na posição estratégica da comunidade (ib.). Em seguida, atribuiu-se uma classificação a cada item, indicando se a sua força ou fraqueza é máxima (3), média (2) ou mínima (1) para a comunidade, em função da resposta que a comunidade tem a esse item. Efectuando o produto entre a relevância e a classificação obtém-se a pontuação. Neste momento, cada item enumerado na matriz SWOT tem uma pontuação associada e pode-se efectuar a intercepção dos pontos endógenos e exógenos da matriz SWOT, como indicado na Figura 7 (ib.).

Figura 1 - Esquema da análise SWOT avançada considerada
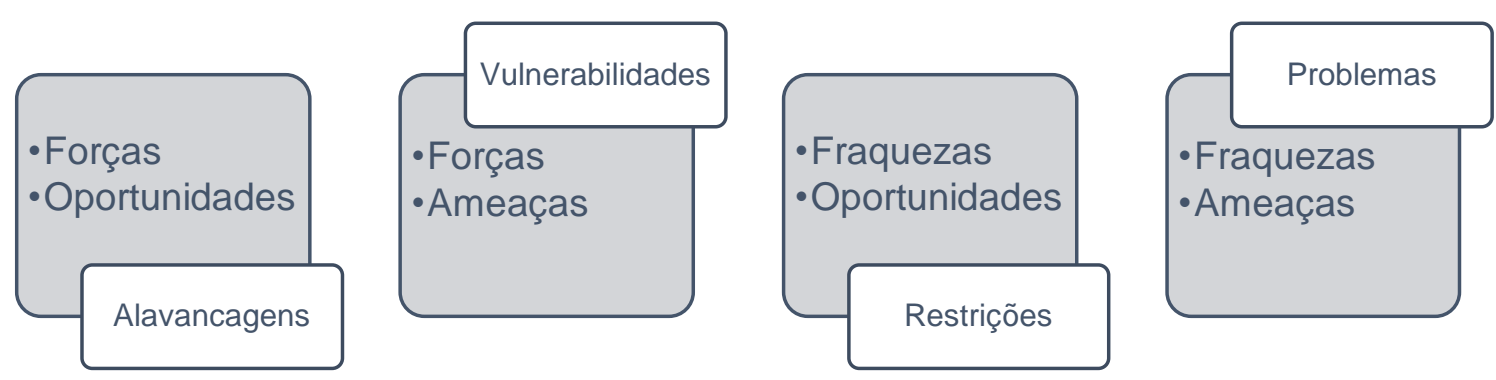

Fonte: Autores 
Deste modo definem-se os seguintes pontos (ib.):

- Alavancagens - são forças que estão ou podem estar ligadas às oportunidades e que permitem o crescimento e a evolução da comunidade.

- Vulnerabilidades - são as forças que se interceptam com as ameaças não controláveis. As vulnerabilidades podem ser prejudiciais a curto, médio ou longo prazo e têm de terminar, definindo estratégias de defesa.

- Restrições - é a relação entre fraquezas e oportunidades, isto é, o que não pode ser aproveitado pela comunidade, devido às suas fragilidades. Com o devido tempo, estas fraquezas têm de ser eliminadas para que se possam conquistar as oportunidades.

- Problemas - resultam da intercepção entre fraquezas e ameaças, constituindo os verdadeiros problemas que terão de ser resolvidos. Ao resolver os problemas, mantendo-se as ameaças, mas conseguindo transformar as fraquezas em forças, passaremos a ter vulnerabilidades.

A pontuação obtida numa intercepção, consiste na soma de cada item separadamente, por exemplo, se a força 6 (S6) tem pontuação de 0.015 e a oportunidade $4(\mathrm{O} 4)$ tem a pontuação de 0.12 , então a pontuação desta intercepção é de 0.135 , ou seja, a soma das duas pontuações anteriores. Assim, esta alavancagem tem como classificação 0.135 .

As alavancagens (23) são quase tantas como os problemas (25), no entanto as vulnerabilidades (49) são muitas, mas as restrições (13) são relativamente poucas. Deste modo e sumariamente, os resultados obtidos são:

- Os aspectos mais fortes desta comunidade são a sua atractividade para quem vem de fora, a diversidade de emprego, o elevado nível de orgulho da população e o facto da maioria dos principais empregadores serem naturais. Para quem vem de fora, os principais factores de atracção são o espirito de entreajuda que existe e o facto de as pessoas serem relativamente abertas a novas ideias e a novas maneiras de fazer. As campanhas de "comprar local" são também um dos pontos mais importantes para o desenvolvimento da comunidade. O elevado sentido de pertença e orgulho que existe, o optimismo que se vive nesta comunidade, o facto de pensarem que serão capazes de ultrapassar este mau período, e a atitude de "poder fazer" e de acreditar que podem influenciar o futuro são outras alavancagens desta comunidade, que facilita a sua evolução e crescimento. Estas são as alavancagens com maior peso.

- As principais vulnerabilidades encontradas foram o reduzido número de crianças com menos de 14 anos, que é uma vulnerabilidade muito grave, podendo indicar a diminuição do número de famílias jovens e o envelhecimento da população, comprometendo o futuro, apesar do optimismo verificado. Quer o nível de orgulho, quer o sentido de pertença das pessoas nesta comunidade são muito elevados, o que faz com que as pessoas continuem a permanecer e a lutar pela comunidade, cooperando umas com as outras, apesar da conjuntura económica difícil, com desemprego e pobreza. No entanto, tudo isto está ameaçado pelo envelhecimento da população. Está a ocorrer um "reforço" da população idosa, originária de fora da freguesia, que se vem fixar aqui quando entra na idade de reforma, agravando a questão do envelhecimento populacional que tem como consequência o despovoamento do território da freguesia. A propriedade pertencente a naturais não é valorizada e não estão identificadas as empresas em risco de fechar nem quais os 
segmentos de mercado onde interessa investir. Não existindo um plano económico, acresce dificuldade na cooperação entre as organizações e na participação mais activa da população em relação aos assuntos de interesse para a comunidade. $A$ mudança de mentalidades é dificultada pelo facto da educação tradicional não ser valorizada e também pelo facto de não existirem oportunidades de emprego para jovens com grau superior.

- Apesar do elevado número de grupos informais, organizações e associações, as reuniões públicas são pouco frequentadas, não sendo aproveitada a oportunidade de poderem exprimir opiniões, em parte porque não se tem uma percepção clara se essa participação influencia ou não as decisões mais importantes. Por outro lado, esta atitude não ajuda a modificar a maneira de pensar que a crise económica potencia. Estes pontos são as restrições mais importantes encontradas. O facto de não actuarem quando o assunto envolve vizinhos, dificulta a expressão de opiniões e a mudança de atitudes. Quem voltou à freguesia por ter perdido o emprego nos grandes centros urbanos são, normalmente, quadros sem qualificação. A questão da valorização da educação pode ser melhorada, uma vez melhoradas as acessibilidades, o acesso ao conhecimento, a novas oportunidades de mercado, facilitando a criação de novos produtos.

- O desemprego e o envelhecimento da população são os principais problemas encontrados. A não existência de um plano económico para a comunidade, definido pela comunidade é outro problema, pois com este plano poder-se-ia concentrar recursos e esforços, definindo-se estratégias para se atingir um objectivo comum. A gestão de fundos próprios e a classificação profissional estão relacionadas com o facto de não serem valorizadas as empresas propriedade de naturais da freguesia e as empresas em risco de fechar não serem identificadas, o que não permite direccionar recursos nem definir segmentos de mercado que poderiam gerar mais bem-estar à população, tornando atraente, por exemplo, o investimento na própria formação, com o objectivo de responder às solicitações que foram aparecendo. Outro problema são as mentalidades, que deveriam ser alteradas: a maioria continua a pensar que a solução reside na fixação de uma grande empresa que emprega um número elevado de pessoas. A alteração das mentalidades só se consegue com formação, aprendizagem e boas vias de comunicação.

Esta freguesia está muito vulnerável, sofrendo muitas ameaças externas, que dificultam o aproveitamento das forças que tem. Apesar das suas fraquezas, a comunidade vai aproveitando algumas das oportunidades que surgem, não apresentando muitas restrições. Há problemas que são de difícil resolução, mas, tirando partido e aumentando o melhor que tem esta comunidade - as alavancagens - é possível que se venham a resolver muitos dos problemas apontados.

\section{Sugestões para o desenvolvimento desta freguesia}

As comunidades como a de Cernache do Bonjardim têm uma grande necessidade de serem revitalizadas, repovoadas e até reinventadas, mas isso não é tarefa fácil num contexto urbano/rural que é exigido a estes territórios.

Sendo uma comunidade essencialmente rural e muito ligada à agro-pecuária, a primeira sugestão que ocorre é a agricultura biológica, dado que, havendo apoio e orientação por parte das entidades competentes, a transição da agricultura 
tradicional actualmente praticada, para a produção biológica, não seria muito difícil e poderia ser uma fonte de desenvolvimento.

Parte ou toda a freguesia de Cernache poderia ser abordada como um "parque cultural”, entendido como (FILIPE; DE MASCARENHAS, 2010, p. 373):

\begin{abstract}
um modelo de participação activa cujos objectivos e aplicabilidade se encontram relacionados com a conservação e valorização das paisagens culturais, a melhoria da qualidade de vida da população rural, a preservação da memória local, novas práticas de desenvolvimento sustentável e o incremento de novas áreas do conhecimento e de aprendizagem. Contribui também para uma compreensão integrada dos valores paisagísticos.
\end{abstract}

Exemplos de parques culturais enumeram-se, por exemplo, o Parque Cultural Vila de São Vicente no centro de São Paulo, Brasil e o Parque Cultural de Westergasfabriek em Amesterdão, Holanda, que foram recuperados, reutizados e dinamizados.

A freguesia em estudo demonstrou, desde muito cedo, propensão para as artes; deste modo, o chamado "teatro de rua" poderia funcionar como um chamariz; festivais de música atraem milhares de pessoas, como em Paredes de Coura, uma pequena povoação no Norte de Portugal; toda a freguesia pode funcionar como um enorme cenário para exposição de escultura, que ficam expostas pelas povoações, constituindo também formas artísticas de diferenciação, como se passa em Hecho, Aragão (Espanha) (Figura 8).

\title{
Figura 8. Exemplo de esculturas expostas na aldeia de Hecho, Aragão (Espanha)
}

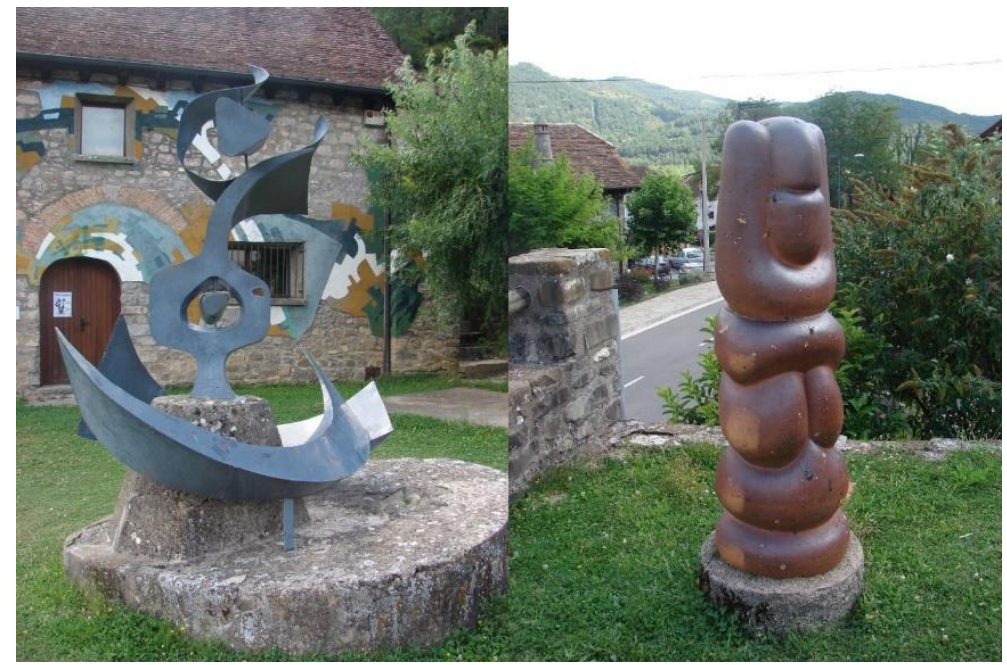

Fonte: Autores. 
Tirando partido das produções tradicionais, algumas delas de excelente qualidade - azeite, mel, vinho, queijo de cabra e ovelha, frutas e legumes - a criação de pequenas indústrias de conservas artesanais, incentivando a auto-suficiência, poderia dar novo fôlego à economia local; a manteiga e o leite de cabra não são explorados actualmente.

Esta freguesia ainda possui um potencial económico não aproveitado, em relação ao comércio étnico, ao artesanato ou à valorização eco cultural, conjugando a Natureza, a paisagem e a cultura para promover a diferenciação territorial. Uma divulgação eficaz do património material e imaterial desta freguesia, como forma de reafirmar a identidade local, pode ter como consequência a sua recuperação e protecção, que urge.

Tendo em vista a recuperação demográfica, a criação de meios económicos e de crédito especialmente destinado a jovens residentes ou naturais da freguesia para a reconstrução das antigas casas em ruinas que se encontram pela freguesia, permitirá o restauro e a conservação do património que (ainda) existe. Acções deste género foram levadas e cabo em Querença, Portugal, com bons resultados.

Tirar partido e valorizar o património natural que existe, completando alguns dos circuitos pedonais e de BTT, acrescentando passeios de barco e desportos náuticos, já que a freguesia tem esse potencial subaproveitado, a criação de um centro de estágio para desportos náuticos em águas tranquilas (remo, canoagem, modelismo náutico...), podem ser outras medidas.

O turismo em espaço rural é outra das hipóteses de dinamização que existe, recuperando a arquitectura característica do local. A participação em trabalhos agrícolas (agro-turismo), a participação em actividades de preservação ambiental (ecoturismo), o turismo de aventura, o cultural, o de interior são apenas algumas formas de turismo alternativo que podem ser implementados nesta freguesia.

O alojamento particular, do género "Alojamento Local" ou B\&B (bed and breakfast), a construção de albergues, reabilitando as imensas quintas e solares da freguesia, ou os "hostel", são várias sugestões de alojamento alternativo, uma vez que o alojamento é um ponto relativamente fraco da freguesia.

No Bregenzer Wald, na Áustria, existe o chamado "bilhete turístico" para quem pernoita duas ou mais noites, dando direito a usufruir gratuitamente de diversas infra-estruturas, como sejam transportes públicos, museus ou piscinas, por exemplo, conseguindo-se que os turistas fiquem por mais do que um dia. Este tipo de estratégia também é uma ideia interessante para Cernache.

A maioria destas sugestões exigem mais organização do que investimento financeiro, sendo de fácil implementação e têm a particularidade de poder dinamizar esta freguesia, fazendo com que haja um maior dinamismo económico de pequena escala.

\section{Comentários finais}

Actualmente, as comunidades rurais, como a de Cernache, são consideradas uma oportunidade, apresentando capacidades competitivas, pois o que se considera como atraso pode, na realidade, ser uma potencialidade, principalmente sob o ponto de vista da sustentabilidade e da resiliência. 
A identificação dos vários pontos fortes e fracos que a comunidade cernachense possui é muito importante para definir o rumo a tomar, reforçando a sua resiliência. Esta comunidade apresenta um saldo positivo dos aspectos internos, com mais forças do que fraquezas, mas os aspectos externos, como as ameaças e as oportunidades, apresentam um saldo negativo. No entanto, em relação aos factores endógenos, alterar a situação actual apenas depende da comunidade; já em relação aos factores exógenos, sendo feito algum trabalho interno, também se torna possível melhorar um pouco a situação.

A freguesia está muito vulnerável, dificultando o aproveitamento e desenvolvimento das suas forças, pois sofre muitas ameaças externas. No entanto, não apresenta muitas restrições, aproveitando algumas oportunidades que surgem.

Melhorando as suas alavancagens, que é o que de melhor esta comunidade possui, conseguem-se atenuar alguns problemas de difícil resolução.

Como conclusão das análises efectuadas, pode-se afirmar que a freguesia de Cernache do Bonjardim tem uma resiliência inerente que lhe permite sobreviver, reagir e reorganizar-se aos vários contratempos que tem sofrido. Já o provou no passado, prova-o no presente e espera-se que venha a provar no futuro. Tudo indica que sim.

No entanto, a desertificação e o envelhecimento da população são importantes ameaças ao futuro desta comunidade pois têm, para além de consequências directas, consequências indirectas que influenciam muitos pontos que caracterizam esta comunidade.

\section{Notas e agradecimentos}

O texto está escrito em português prévio ao Acordo Ortográfico.

Os autores gostariam de agradecer a Michele Collussi a disponibilidade em nos ajudar na aplicação do método e a todos os cernachenses que participaram nos inquéritos permitindo a realização desta análise.

\section{REFERÊNCIAS}

A Declaração de Cork. LEADER Magazine, [s. I.], p. 1-2, 1996. AGÊNCIA PORTUGUESA DO AMBIENTE. Barragens de Portugal. [s.d.]. Disponível em:

<http://cnpgb.apambiente.pt/gr_barragens/gbingles/FichasIng/CastelodoBodefichal ng.htm>. Acesso em: 9 fev. 2018.

Aprenda a análise SWOT com modelo no EXCEL. [s.d.]. Disponível em: <http://scientiaarca.com.br/analise-swot-excel/>. Acesso em: 1 mar. 2016.

BARROS, R. Fogo de Pedrógão Grande é o $11 .^{\circ}$ mais mortal do mundo desde 1900, 2017. Disponível em: 
<http://rr.sapo.pt/especial/86656/fogo_de_pedrogao_grande_e_o_11_mais_mortal_ do_mundo_desde_1900>Acesso em: 4 ago. 2018.

COLUSSI, $M$. The community resilience manual. A resource for rural recoverty and renewal. Port Alverni: Centre for Community Enterprise, 2000.

CORREIA, J. A.; FIGUEIREDO, E. A voz às comunidades rurais: animação e comunicação para o desenvolvimento. In: IV CONGRESSO DE ESTUDOS RURAIS MUNDOS RURAIS EM PORTUGAL - MÚLTIPLOS OLHARES, MÚLTIPLOS FUTUROS 2010, Aveiro. Anais... Aveiro, 2010.

DIÁRIO DE NOTÍCIAS. Incêndios: quase 53 mil hectares arderam na região centro dados provisórios, 2017. Disponível em: <https://www.dn.pt/lusa/interior/incendiosquase-53-mil-hectares-arderam-na-regiao-centro---dados-provisorios-8586699.html> Acesso em: 4 ago.2018

DOS SANTOS, F. T. Territórios resilientes enquanto orientação de planeamento. Prospectiva e Planeamento, [s. I.], v. 16, p. 13-28, 2009.

EDWARDS, W. Building the foundations of resilient communities. A resilient nation is anchored by resilient communities. 2011. Disponível em: <icma.org/pm>. Acesso em: 7 out. 2012.

FERNANDES, A. M. O discurso de reinvenção da ruralidade - exigências, expectativas e representações urbanas na construção de uma ruralidade consumível. In: IV CONGRESSO DE ESTUDOS RURAIS - MUNDOS RURAIS EM PORTUGAL - MÚLTIPLOS OLHARES, MÚLTIPLOS FUTUROS 2010a, Aveiro. Anais... Aveiro

FERNANDES, G. P. Perspectivas de gestão e políticas de valorização do território na Cordilheira Central. In: IV CONGRESSO DE ESTUDOS RURAIS - MUNDOS RURAIS EM PORTUGAL - MÚLTIPLOS OLHARES, MÚLTIPLOS FUTUROS 2010b, Aveiro. Anais... Aveiro

FILIPE, M.; DE MASCARENHAS, J. M. Aldeias abandonadas e preservação do património cultural e paisagístico: linhas mestras para a sua recuperação e valorização multifuncional. A Aldeia das Broas como estudo de caso. In: IV CONGRESSO DE ESTUDOS RURAIS - MUNDOS RURAIS EM PORTUGAL - MÚLTIPLOS OLHARES, MÚLTIPLOS FUTUROS 2010, Aveiro. Anais... Aveiro

GONÇALVES, M. M. El conocimiento del patrimonio en cuanto factor de estructuración de la sostenibilidad de los territorios. El caso de la freguesia de Cernache do Bonjardim, Portugal. 2016. Sevilla, [s. I.], 2016. Disponível em: <https://www.educacion.gob.es/teseo/mostrarSeleccion.do>

GONÇALVES, M. M.; ROSENDAHL, S. Análise de vários factores que influenciam a definição das chaves do território: o caso da freguesia de Cernache do Bonjardim. 
In: PLURIS2010 $4^{\circ}$ Congresso Luso-Brasileiro para o Planeamento Urbano, Regional, Integrado, Sustentável. Faro: Universidade do Minho, 2010. p. paper 336.

GONÇALVES, M. M.; ROSENDAHL, S. Impacte das grandes obras de engenharia. A barragem do Castelo do Bode e a freguesia de Cernache do Bonjardim. In: ICEUBI2011 International Conference on Engineering UBI2011 Innovation \& Development. Covilhã: Edições UBI 2011, 2011. p. Paper 39.

GONÇALVES, M. M.; ROSENDAHL, S.; PEREZ-CANO, M. T. A new phoenix from the ashes? In: European Association of Urban History (EAUH) 2018. Rome. p. In print. Grandes incêndios em Portugal. Uma história que começou em 1986. 2017.

Disponível em:

<http://rr.sapo.pt/noticia/86522/grandes_incendios_em_portugal_uma_historia_que _comecou_em_1986>.Acesso em: 27 jul. 2018.

MENDES, E. Dornes, o tesouro dos Templários. Dornes: Junta de Freguesia de Dornes, 2009.

MOREIRA, M. B. Inovação e empreendedorismo em zonas rurais desfavorecidas. In: IV CONGRESSO DE ESTUDOS RURAIS - MUNDOS RURAIS EM PORTUGAL MÚLTIPLOS OLHARES, MÚLTIPLOS FUTUROS 2010, Aveiro. Anais... Aveiro

NATÁRIO, M. M. S.; BRAGA, A. M. M.; REI, C. M. A valorização dos recursos endógenos no desenvolvimento dos territórios rurais. In: PLURIS2010 $4^{\circ} \mathrm{CONGRESSO} \mathrm{LUSO-BRASILEIRO} \mathrm{PARA} \mathrm{O} \mathrm{PLANEAMENTO} \mathrm{URBANO,} \mathrm{REGIONAL,}$ INTEGRADO, SUSTENTÁVEL 2010, Faro. Anais... Faro: Universidade do Minho, 2010. Disponível em: <http://pluris2010.civil.uminho.pt/actas.zip>

PACHON, F.; MARTÍNEZ, N. Marca del territorio como instrumento de identidad, conservacion de recursos ambientales y comercio justo para la localidad de Paramo Sumapaz. In: $17^{\circ} \mathrm{CONGRESSO}$ DA APDR E $5^{\circ} \mathrm{CONGRESSO} \mathrm{DE} \mathrm{GESTÃO} \mathrm{E}$ CONSERVAÇÃO DA NATUREZA, CONGRESSO INTERNAIONAL DA APDR/AECR 2011, Bragança-Zamora. Anais... Bragança-Zamora: Associação Protuguesa para o Desenvolvimento Regional, 2011. Disponível em: <http://www.apdr.pt/congresso/2011/ACTAS_PROCEEDINGS.html> Acesso em: 21 nov.2012

PIKE, A.; DAWLEY, S.; TOMANEY, J. Resilience, adaptation and adaptability. Cambridge Journal of Regions Economy and Society, [s. I.], n. 3, p. 59-70, 2010. SÁNCHEZ ARROYO, R. M.; HERRERA PEREA, J. Veredas: una actividad tradicional sostenible. Sumuntán, [s. I.], n. 8, p. 69-85, 1997.

SHUMAN, M. Revitalizing communities from the inside out. In: GORDON, P.; COLUMBIA INSTITUTE (Eds.). Resiliency. Cool ideas for locally elected leaders. Vancouver: Centre for Civic Gouvernance, Columbia Institute, 2011. p. 70-84. 
Marta Marçal Gonçalves. Engenheira Civil (Instituto Superior Técnico, Lisboa, Portugal), doutora em Urbanística e Ordenamento do Território (Universidad de Sevilla, Espanha), Assistente de $2^{\circ}$ Triénio da Universidade do Algarve, Portugal. mgoncal@ualg.pt

María Teresa Pérez Cano. Arquitecta (Universidad de Sevilla, Espanha), doutora em Urbanística e Ordenamento do Território (Universidad de Sevilla, Espanha), Professora na Universidad de Sevilla, Espanha. tpcano@us.es

Stefan Rosendahl. Geólogo (Stuttgart Universität, Deutschland), doutor em Ciências da Natureza (Stuttgart Universität, Deutschland), Professor Associado no Instituto Superior Dom Dinis, Marinha Grande, Portugal. srosendahl56@gmail.com

Como citar: GONÇALVES, Marta Marçal; CANO, María Teresa Pérez; ROSENDAHL, Stefan. Resiliência de comunidades rurais: a freguesia de Cernache do Bonjardim, Portugal. Redes, Santa Cruz do Sul, v. 24, n. 2, p. 162-185, maio 2019. ISSN 1982-6745. Disponível em: https://doi.org/10.17058/redes.v24i2.13201. 